\title{
1 Differences in word learning: bilingualism or 2 linguistic experience?
}

3 Maria Borragan ${ }^{1}{ }^{*}$, Angela de Bruin ${ }^{1}$, Viktoria Havas ${ }^{2}$, Ruth de Diego-Balaguer ${ }^{3}$, Mila

4 Dimitrova Vulchanova ${ }^{2}$, Valentin Vulchanov ${ }^{2}$, Jon Andoni Duñabeitia ${ }^{4}$

$5{ }^{1}$ BCBL, Basque Center on Cognition, Brain and Language, San Sebastian, Spain;

62 NTNU, Norwegian University of Science and Technology, Dragvoll, Norway;

73 Universitat de Barcelona, Barcelona, Spain;

84 Universidad Nebrija, Madrid, Spain

9

*Corresponding Author's contact :

Basque Center on Cognition, Brain and Language (BCBL)

Paseo Mikeletegi 69

20009

Donostia - Spain

\section{Abstract}

Bilinguals may be better than monolinguals at word learning due to their increased experience with language learning. In addition, bilinguals that have languages that are orthotactically different could be more used to dissimilar orthotactic patterns. The current study examines how bilinguals with languages that are orthotactically similar and dissimilar and monolinguals learn novel words that violate or respect the orthotactic legality of the languages they know and how this learning may be affected by the similarity between the bilinguals' two languages. In Experiment 1, three groups of children were tested: monolinguals, Spanish-Basque bilinguals (dissimilar orthotactic languages), and Spanish-Catalan bilinguals (similar orthotactic languages). After an initial word learning phase, they were tested in a recall task and a recognition task. Results showed that Spanish-Basque bilingual children performed differently than the other two groups. While Spanish monolinguals and Spanish-Catalan bilinguals recognized illegal words worse than legal words, Spanish-Basque bilinguals showed equal performance in learning illegal and legal patterns. A replication study conducted with two new groups of Spanish-Basque children (one group with high Basque proficiency and one group with a lower proficiency) indicated that the effects were not driven by the proficiency in the second language since a similar performance on legal and illegal patterns was observed in both groups. In Experiment 2, two groups of adults, monolinguals and Spanish-Basque bilinguals, were tested with the same task used in Experiment 1. The effect seen in children seems to be absent in adults. Spanish-Basque bilingual adults showed better overall learning performance than monolinguals, irrespective of the illegality of the items. Differences between groups could be due to the effect of having acquired literacy and linguistic competence. 


\section{Introduction}

Bilingualism is no longer an exceptional linguistic reality and knowing more than one

language is required for business, education, and to communicate with others in many modern

societies. Thus, bilingualism has become an important research area in the last decades.

Despite the increasing number of studies exploring the effects of bilingualism on domaingeneral and domain-specific cognitive processes [1-3], the impact of bilingualism on language learning has received less attention. Previous work has suggested that bilinguals may be better at word learning than monolinguals due to their experience with language learning (see [4]). However, it is not clear whether bilinguals in general are better at word learning or whether these effects are related to and dependent on the specific characteristics of the two languages they have mastered.

Bilinguals know that objects may have different names in each of their languages and may therefore link translations in another new language more easily to a known concept than monolinguals. Along this line, studies focusing on the bilinguals' and monolinguals' capacity to learn a third language have suggested that bilinguals achieve a higher proficiency level in the new language than their monolingual peers $[5,6]$. This learning benefit has been observed both for bilinguals who learned their languages in a classroom environment $[7,8]$, as well as for bilinguals who had acquired both languages from birth [4,9]. For instance, the latter two studies were based on a word-learning task that included novel words created to be phonologically unfamiliar to the participants. Bilingual learners had highly contrasting language combinations, such as Spanish-English or Mandarin-English. The new words had to be learned as translation equivalents of existing words from the participants' native language. Results showed that bilinguals outperformed monolinguals in their learning performance (see [10], for review). Similar findings were also observed by Kaushanskaya and Rechtzigel [11] in a study in 
their memory span. Bilinguals outperformed both groups of monolinguals when learning novel words irrespective of the specific phonological features of the novel words and the memory span of the participants.

However, these findings do not necessarily imply that all types of bilinguals will learn novel words better than monolinguals. Werker \& Byers-Heinlein [12] underscore the importance of the specific language pairs in the bilingual language system and their interaction. As seen, the abovementioned studies tested bilinguals who mastered two languages with clearly different orthotactic and phonotactic structures (e.g., Mandarin-English or Spanish-English), and it could be tentatively hypothesized that this is the underlying factor that makes the learning of new items more effective for bilinguals. Different bilingual populations speak different languages and the characteristics of the specific languages spoken may affect how known pieces of information are processed and, more importantly for the purposes of the current study, how new pieces of information are learned. Studies suggest that the structure of one's known language(s) may determine the way new sounds are processed [13]. Furthermore, Bialystok et al. [2] demonstrated that bilinguals whose two languages share the same print-to-sound principle and/or the same writing system (i.e., Spanish-English) show better performance in a meta-phonological task (count the number of sounds in a word) than bilinguals with two languages following a different writing system (i.e., Chinese-English). Certainly, learning new phonological and orthographic patterns that also exist in one's native language(s) is expected to be easier that learning completely different patterns (see [14]). Thus, the current study examines how bilinguals and monolinguals learn words that violate or respect the orthotactic legality of the languages they know (i.e., the language-selective pattern of grapheme combinations in written words), and how this learning may be affected by the similarity between the bilinguals' two languages. To this end, the performance of two groups of bilinguals was compared to that of a group of monolinguals. 

not exist in their languages, the degree of dissimilarity between the two languages could improve learning of these different structures or patterns. Daily management with different orthotactic patters could lead these bilinguals to be more flexible when encountering new patterns. Thus, we also conjectured that bilinguals that know languages with different orthotactics rules are more prone to accept and learn new words with different orthotactic characteristics than bilinguals with languages that are orthotactically similar. words during bilingual visual-word recognition ([15-17], for review). Words from a given language that include certain letter combinations that are illegal in the other language known to a bilingual (namely, marked words containing language-specific orthotactic regularities) are processed differently than words whose orthotactic pattern is also plausible in the other language (namely, unmarked words; [18]). Language detection is mediated by the regularities of the sub-lexical representations of the words that are being read. Along these lines, research has demonstrated that marked words are easier to detect than unmarked words [18-20], and that they elicit lower cross-language activation levels than unmarked words [17], suggesting that language-specific orthotactic patterns represent an important cue in bilingual language processing.

With this in mind, here we investigated the extent to which monolinguals and different types of bilinguals whose language combinations critically vary in their orthotactic overlap learn new words in a different manner depending on the sub-lexical characteristics of the items. We focused on two language pairs: Spanish-Catalan and Spanish-Basque. While these 
116 in their graphemic structure, and Basque has many bigram combinations that are illegal

117 according to the Spanish (and Catalan) orthotactic rules.

In the first series of experiments (Experiments 1a and 1b) we will focus on children, and then the same questions will be put at test in adult samples (Experiment 2) to explore the degree of generalization across age groups and the extent to what the effects may depend on a multilingual school environment. Bilingual children attending a bilingual school need to deal with the two languages in printed materials in the same school context. They have to read in both languages and they are permanently exposed to bilingual written language. This scenario of bilingual schools where the two languages coexist are markedly different from adults' common contexts, in which the exposure to two written languages is far less common in the same scenario. Thus, children may develop strategies different than adults to deal with this reality and its demands. Hence, we investigated if new vocabulary acquisition is easier for all types of bilinguals as compared to monolinguals (see [11]), or if this benefit depends on the specific sub-lexical characteristics of the language combination of the bilinguals, paying special attention to the orthotactic level. the specific sub-lexical characteristics of the words that are being learned. To this end, we created non-existing novel orthographic representations that either respected the orthotactic structure of all the languages (e.g., the new word 'aspilto', which could perfectly be a word in any of the three languages according to the graphemic patterns), or that violated the orthotactic rules of these languages (e.g., the nonword 'ubxijla', containing the bigrams 'bx' and 'jl' that do not exist in Spanish, Catalan or Basque). We predicted that the learning benefit would be either maximal for bilinguals with more dissimilar languages at the orthotactic level on the illegal bigram combinations, since they could find it easier to deal with different orthotactic patterns due to their experience. 


\section{Experiment 1a}

\section{Methods}

Participants. A total of 72 children ( 45 females; $\mathrm{M}_{\mathrm{age}}=12.9$ years, $\mathrm{SD}_{\mathrm{age}}=0.8$ ) took part in

this experiment, divided into three language groups. Children were recruited from three

schools located in different Autonomous Communities in Spain. First, a group of 24 Spanish

monolinguals was recruited in Santander (Cantabria), which is a monolingual region located in

(Catalunya), a bilingual community on the North East coast. And third, a group of 24 SpanishNorth coast. monolingual school. Spanish-Catalan bilingual children had acquired both languages before the age of 6 . They were raised in a bilingual community and educated in a Spanish-Catalan bilingual school. Spanish-Basque bilinguals had also acquired both languages before the age of 6 , and they were also attending a bilingual school. We assessed language proficiency with

157 three different measurements (see Table 1): a subjective scale, in which participants rated their language competence on a scale from 0 to 10; a 20-item adapted version of a picture naming task [21]; the LexTale (a lexical decision task, cf., for the English version [22]; for the Spanish version [23]; and for the Basque version [21]). In addition to measuring proficiency in Spanish, Basque, and Catalan (where relevant), we also made sure that, despite English being a mandatory subject in all Spanish schools, the participants' English level was relatively low as assessed by the English LexTale (see Table 1). 
Table 1. Descriptive statistics of assessments.

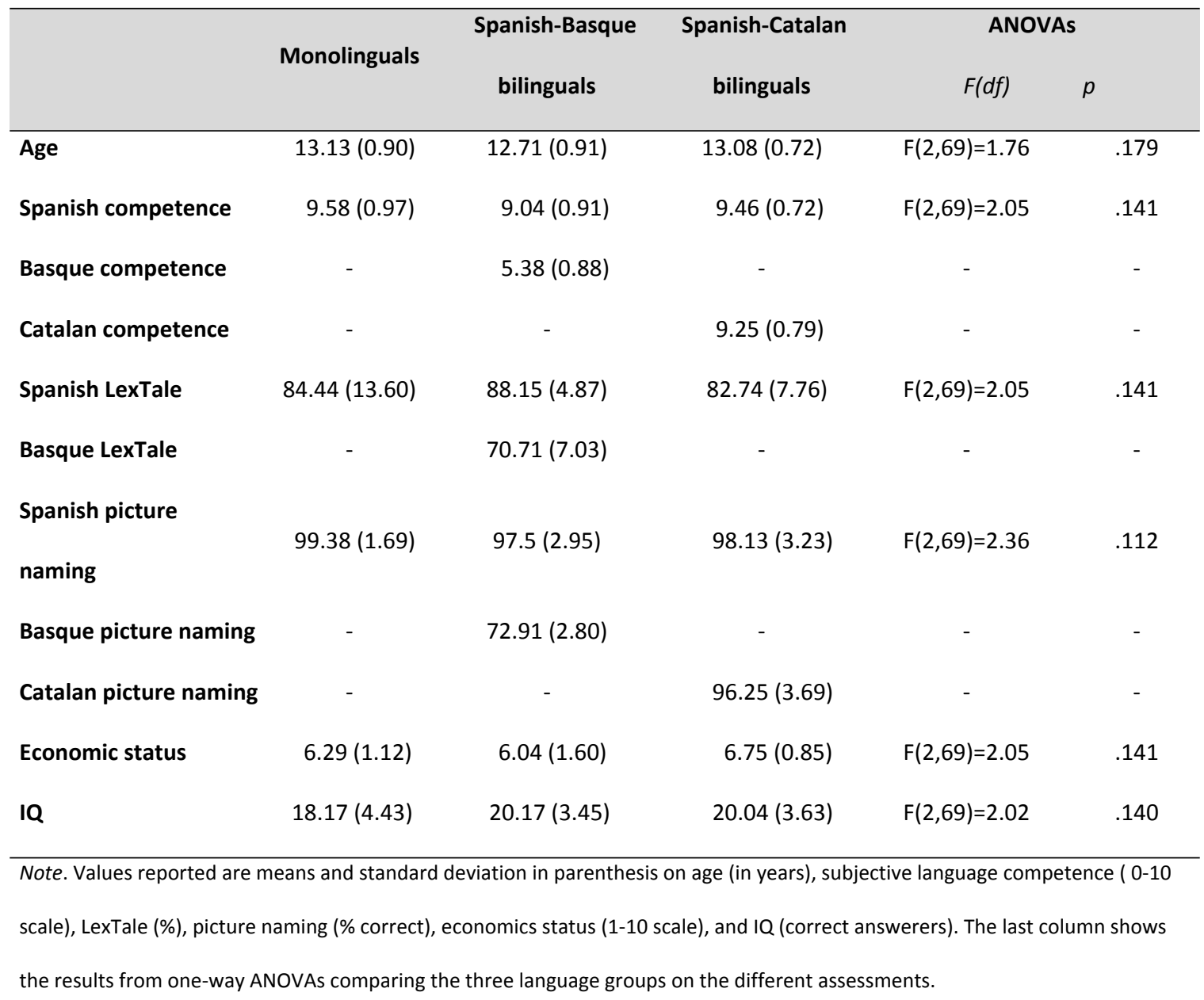

Participant groups were matched in age, language proficiency in Spanish, socioeconomic status, and IQ (see Table 1). Socioeconomic status was measured with a short parental questionnaire in which they were asked to indicate on a scale from 1 to 10 how they perceived their economic situation as compared to other members of their community [24]. IQ was measured with a 6-minutes abridged version of the K-BIT [25] in which participants had to complete as many matrices as they could in the time provided. As seen in Table 1, bilingual participants could not be matched on their second language competence (i.e., Basque and

177 Catalan). Spanish-Basque bilinguals were less proficient in Basque than the Spanish-Catalan 
bilinguals were in Catalan, and this may be due to the origin of the Spanish-Basque bilinguals,

179 who come from and were tested in a city in which Basque is mainly used at school, while the Spanish-Catalan participants used Catalan in daily life outside school too.

All participants were right-handed and none were diagnosed with language disorders,

learning disabilities, or auditory impairments. They and their families were appropriately informed and legal guardians signed consent forms prior to the experiment. The protocol was carried out according to the guidelines approved by the BCBL Ethics Committee. consonant bigram, and final vowel (i.e., VCCVCCV). The consonantal bigram was manipulated to be legal or illegal in the three critical languages (i.e., half of them resulting in legal and half of them in illegal strings). The fifteen strings containing legal consonant bigrams (e.g., 'ASPILTO') included bigram combinations that were plausible in Spanish, Catalan and Basque (e.g., the consonant cluster 'SP' appears in 'avispa', the Spanish for wasp, 'ispilu', mirror in Basque, and 'espai', which corresponds to space in Catalan). The other 15 strings contained two consonant clusters that corresponded to illegal bigram combinations in all three languages (e.g., 'UBXIJLA', where the bigrams 'BX' and 'JL' do not exist in any of the three critical languages). The average bigram frequency of the legal words in the three languages did not

197 statistically differ ( $p>.15$; see Appendix). Each of the 30 strings was paired with a different video clip of an invented 3D object that rotated on 3 axes (see [26]). The new word stimuli were recorded in a soundproof room with a Marantz ${ }^{\circledR}$ professional PMD671 recorder by a native Spanish female with neutral intonation. Legal and illegal items could be pronounced and 
Procedure. Participants were individually tested during school hours. The entire experiment

lasted about one hour, including the initial assessment and the two experimental phases (i.e., presented for $6500 \mathrm{~ms}$. Each 3D object was visually presented together and aligned in time with the onset of the presentation of the visual (written) and auditory representations of the corresponding novel word to show how they could sound. After the $6500 \mathrm{~ms}$, participants were presented with a screen requiring them to type on the keyboard the name of the object they had just learned, and they could only continue to the next trial if the string had been written correctly. Each 30 object-string association was presented three times during the learning phase, leading to 90 trials that were presented in a random order. first completed a recall task in which they saw each 3D object and had to write down the corresponding name that they had learned before. They were instructed to type the string that they thought corresponded to each object, even if they did not remember the whole string. After entering their responses to the objects presented in a random order, they were asked to complete a recognition task. In each of the trials of the recognition task, participants were presented with a fixation cross displayed for $500 \mathrm{~ms}$, immediately followed by the centered presentation of the 3D object accompanied by two response options (a correct and an 
to strings that were presented during the learning phase, but were shuffled so that they did not match the correct objects. The location of correct and incorrect options was counterbalanced across trials. Participants responded by pressing one out of two buttons on the keyboard corresponding to the location of the correct response. If no answer was given in $10000 \mathrm{~ms}$, the next 3D object was presented.

Data analysis. Firstly, a series of repeated measures ANOVAs were carried out considering the absolute number of correctly recalled items from the set of 30 . Second, and taking into account that recall was predicted to be markedly low given the difficulty of the task and the number of items, we calculated the Levenshtein Distance (corresponding to the number of single-character substitutions, deletions, or insertions needed in each response to match the target string), and we used this as the dependent variable. A lower number of edits indicated that the response was closer to the target. In the recognition task, accuracy of the probability that the data were observed under the alternative hypothesis versus the null hypothesis. For instance, $B F_{10}=5$ indicates that the observed data were five times more likely to have occurred under the alternative than the null hypothesis, or in the opposite way, a $B F_{10}$

$250=.2$ shows that the data were more likely to be observed under the null than the alternative hypothesis. Analyses were conducted with JASP 0.8.5. 


\section{Results and Discussion}

In the recall task, participants recalled more legal orthotactic sequences than illegal

orthotactic sequences (see Table 2$), F(1,69)=22.93, p<.001, \eta_{p}^{2}=.247$. However, the main effect of Group was not significant, $F(2,69)=0.21, p=.813, \eta_{p}^{2}=.006$., and the interaction between

$\eta_{p}^{2}=.010$, and the interaction between the two factors were not significant, $F(2,69)=0.35$ $p=.704, \eta_{p}^{2}=.006$

Table 2. Descriptive statistics for the Recall task and the Recognition task.

\begin{tabular}{lllllll}
\hline & \multicolumn{2}{c}{ Monolinguals } & \multicolumn{2}{c}{ Spanish-Basque bilinguals } & \multicolumn{2}{l}{ Spanish-Catalan bilinguals } \\
& Legal & Illegal & Legal & Illegal & Legal & Illegal \\
\hline Recall task & & & & & & \\
Recalled items & $3.33(5.2)$ & $0.28(1.36)$ & $2.78(3.89)$ & $0.28(1.36)$ & $4.17(7.57)$ & $0(0)$ \\
LD & $5.83(0.6)$ & $6.24(0.49)$ & $5.76(0.66)$ & $6.16(0.38)$ & $5.66(0.68)$ & $6.19(0.41)$
\end{tabular}

Recognition task

\%error

$$
30.28(16.21)
$$

$1994(628)$

$2112(716)$ languages groups. sequences tended to need more time to be responded than legal ones (see table 2), however this effect was not significant, $F(1,69)=2.90, p=.093, \eta_{p}^{2}=.040$. Also, the main effect of Group 
272 was not significant, $F(2,69)=0.07, p=.932, \eta_{p}^{2}=.002$, and the interaction between Orthotactic

273 structure and Group was not significant either, $F(2,69)=0.57, p=.567, \eta_{p}^{2}=.016$. This means that

274 all groups invested the same amount of time in all responses, with a slight tendency towards

275 greater effort for illegal sequences. In terms of accuracy, there was a significant main effect of

276 orthotactic sequences (see Table 2 ), $F(1,69)=12.85, p<.001, \eta_{p}^{2}=.145$. Overall, participants

277 were more accurate at recognizing the correct word for the object when it was a legal

278 orthotactic sequence than an illegal one. On the other hand, the main effect of Group was not

279 significant, $F(2,69)=0.098, p=.907, \eta_{p}^{2}=.003$, but the interaction between the two factors was

280 significant, $F(2,69)=3.51, p=.035, \eta_{p}^{2}=.079$. This interaction suggests that the illegality effect

281 differs between the three groups. We therefore assessed this effect in each group separately.

282 Spanish-Catalan bilinguals $\left(t(23)=3.10, p=.005\right.$, Cohen's $\left.d=.633, B F_{10}=8.68\right)$ and monolinguals

$283\left(t(23)=2.97, p=.007\right.$, Cohen's $\left.d=.606, B F_{10}=6.62\right)$ showed a significant effect of illegality. In

284 contrast, this effect was not observed for Spanish-Basque bilinguals $(t(23)=0.099, p=.922$,

285 Cohen's $d=.020, B F_{10}=0.21$ ), showing that they had learned illegal orthotactic sequences to

286 the same extent as legal ones (see Fig 1). To follow up on this interaction, we also looked at

287 the simple main effects of Group on each level of Orthotactic Structure (i.e., on legal and illegal

288 patterns separately). In a one-way ANOVA we found no significant effect of group for the legal

$\left(F\left(2,69=.61, p=.545, \eta_{p}^{2}=.017\right)\right.$ or the illegal orthotactic sequences, $\left(F(2,69)=1.63, p=.203, \eta_{p}^{2}\right.$

$=.045)$. This means that the interaction between group and orthotactic sequence is not driven

by the Spanish-Basque bilinguals performing better on the illegal sequences nor doing worse on the legal ones, simply that they perform the same on legal and illegal patterns whereas the other language groups perform worse on the legal than the illegal sequences. 
300 affects the way they learn new words that violate or respect the orthotactic patterns of the languages they know. We therefore compared monolingual children's performance to that of two groups of bilinguals: one group of (Spanish-Catalan) bilinguals who speak two languages with similar orthotactic patterns and one group (Spanish-Basque) speaking two languages that have different orthotactic patterns. Results in the recall task showed that legal words were remembered better than illegal words, but no differences between the three language groups language group and illegality on accuracy, suggesting that monolinguals, Spanish-Catalan bilinguals, and Spanish-Basque bilinguals differ in the way they learnt new legal and illegal sequences. While monolinguals and Spanish-Catalan bilinguals recognized illegal sequences worse than the legal ones, Basque-Spanish bilinguals did not show this effect. This result suggests that group differences in word learning are not due to bilingualism as such but rather related to the two specific languages that they know. Spanish and Basque are more dissimilar (e.g., in grammar, letter sequences, phonology) than Spanish and Catalan. Therefore, the absence of a legality effect in the Spanish-Basque bilinguals could be due to their linguistic experience with the two distinct languages and the process of literacy acquisition (having already acquired the two languages). In the next experiment (Experiment 1b), we firstly wanted to replicate the null result of illegality in Spanish-Basque bilinguals. Furthermore, as can be seen in Table 1, Basque proficiency in the group of Spanish-Basque bilinguals was lower than the Catalan proficiency in the Spanish-Catalan bilinguals. For this reason, we included two groups of Spanish-Basque bilinguals in Experiment $1 \mathrm{~b}$ : One similar to the previous study and one group with a higher 
324 driven by proficiency differences between the two bilingual groups. In contrast, if we do not

325 observe an illegality effect in either group of Basque speakers in Experiment $1 \mathrm{~b}$, this would

326 support our interpretation that the findings in Experiment $1 \mathrm{a}$ are related to linguistic experience.

\section{Experiment 1b}

\section{Methods}

Participants. Forty-six Spanish-Basque bilingual children took part in this experiment

(34 females; $\mathrm{M}_{\mathrm{age}}=12.9$ years, $\mathrm{SD}_{\mathrm{age}}=0.6$ ). Participants were recruited from two different

Basque communities in the Basque Country. The first group of participants consisted of 22

Spanish-Basque bilinguals from Donostia-San Sebastian, a dense bilingual environment. The

Table 3. Descriptive statistics of assessments

\begin{tabular}{lcccc}
\hline & Highly proficient Basque & Less proficient Basque & \multicolumn{2}{c}{ T-test } \\
& bilinguals & bilinguals & $\mathbf{t}(d f)$ & $p$ \\
\hline Age & $13.05(0.72)$ & $12.79(0.59)$ & $\mathrm{t}(44)=1.31$ & .197 \\
Spanish competence & $9.5(0.86)$ & $9.21(0.59)$ & $\mathrm{t}(44)=1.35$ & .183 \\
Basque competence & $7.68(1.09)$ & $5.71(1.37)$ & $\mathrm{t}(44)=5.38$ & $<.001$
\end{tabular}




\section{Spanish Lextale}

Basque Lextale

Spanish picture naming

Basque picture naming

Socioeconomic status

IQ

\author{
85.87 (5.59)
}

$69.82(7.49)$

$87.73(27.11)$

77.45 (2.69)

$6.55(1.14)$

$18.73(2.12)$
87.05 (5.17)

$71.21(8.60)$

97.71 (4.66)

$67.83(2.45)$

$6.25(1.03)$

$18.38(3.03)$ $t(44)=0.74$

$t(44)=0.58$

$t(44)=0.34$

$t(44)=3.11$

$t(44)=0.92$

$t(44)=0.45$

Note. Values reported are means and standard deviation in parenthesis on age (in years), subjective language competence ( 0-10

As in Experiment 1a, all participants' parents received an information letter and a

parental written informed consent, which was signed and returned before testing. The study

was approved by the BCBL Ethics Committee. None of the children were left-handed and none

were diagnosed with language disorders, learning disabilities, or auditory impairments.

\section{Results and Discussion} times in the recognition task. In the recall task, participants recalled more legal than illegal words (see Table 4), $F(1,44)=13.57, p=<.001, \eta_{p}^{2}=.227$, and the items recalled were closer to the target item in the case of the legal as compared to the illegal words when the Levenshtein 
362 Distance was taken into account (see Table 4), $F(1,44)=26.97, p=<.001, \eta_{p}^{2}=.365$. However,

363 there were no effects of Group on accuracy, $F(1,44)=1.18, p=.282, \eta^{2}=.026$, or Levenshtein

364 distance of the recalled item, $F(1,44)=2.49, p=.122, \eta_{p}^{2}=.054$. There was also no interaction

365 between the illegality effect and Group on accuracy, $F(1,44)=2.09, p=.155, \eta_{p}^{2}=.035$, or

366 Levenshtein distance, $F(1,44)=2.95, p=.093, \eta_{p}^{2}=.040$. In the recognition task, participants

367 required more time to recognize illegal words than legal ones, $F(1,44)=11.78, p=<.001, \eta_{p}^{2}$

$368=.211$, but no differences between groups were observed, $F(1,44)=1.12, p=.296, \eta_{p}^{2}=.025$, nor

369 an interaction, $F(1,44)=0.11, p=.742, \eta_{p}^{2}=.002$. Nevertheless, we observed that participants

370 recognized legal and illegal words equally in terms of percentages of errors, $F(1,44)=2.19$,

$371 p=.146, \eta_{p}^{2}=.047$, and no differences between groups were found, $F(1,44)=0.19, p=.665, \eta_{p}^{2}$

$372=.004$ nor an interaction, $F(1,44)=0.15, p=.699, \eta_{p}^{2}=.003$, showing that the lack of illegality

373 effect was similar for both groups of Spanish-Basque bilinguals (see Fig 2).

Table 4. Descriptive statistics for the Recall task and the Recognition task.

\begin{tabular}{|c|c|c|c|c|}
\hline & \multicolumn{2}{|c|}{ High proficient Basque bilinguals } & \multicolumn{2}{|c|}{ Less proficient Basque bilinguals } \\
\hline & Legal & Illegal & Legal & Illegal \\
\hline \multicolumn{5}{|l|}{ Recall task } \\
\hline Recalled items & $3.03(4.47)$ & $1.21(2.63)$ & $5.56(6.42)$ & $1.39(5.55)$ \\
\hline LD & $5.8(0.50)$ & $6.09(0.43)$ & $5.38(0.92)$ & $5.95(0.69)$ \\
\hline \multicolumn{5}{|l|}{ Recognition task } \\
\hline \%error & $30.61(12.46)$ & $33.94(12.83)$ & $29.72(16.68)$ & $31.67(12.00)$ \\
\hline RT & 1959 (637) & $2153(785)$ & $1755(505)$ & $1991(546)$ \\
\hline \multicolumn{5}{|c|}{ Note. Mean and standard deviation in parenthesis on recalled items (absolute number) and Levenshtein Distance (LD) (Recall ta } \\
\hline
\end{tabular}

Fig 2. Violin plots of the percentage of errors in legal and illegal orthotactic sequences. 
We investigated whether the effects were due to the characteristics of the languages or the proficiency of the children. Thus, Experiment $1 \mathrm{~b}$ aimed to replicate the findings from the Spanish-Basque bilingual children tested in Experiment 1a in two new samples of SpanishBasque bilinguals (a group of more balanced bilinguals and a group with the same proficiency as in Experiment 1). Similar to Experiment 1a, these bilingual children recalled more legal than illegal words, and importantly, they recognized legal and illegal words to the same extent. Furthermore, no differences were observed between these two groups regardless of their proficiency differences, suggesting that the (absence of an) illegality effect was not modulated by proficiency in Basque. Thus, these findings provide support to the results from Experiment 1a, suggesting that linguistic experience with languages that differ from each other at the orthotactic level may modulate word learning in bilingual children.

\section{Experiment 2}

Next, we wanted to test whether the same differential pattern observed in Spanishorthographic markedness during new word learning (e.g. flexibility in word learning) diminish as a function of age. We therefore conducted a study using the same methodology as in experience speaking two different languages affects learning new legal versus illegal words across the lifespan, we would expect patterns similar to those reported in Experiment 1 (i.e., 
407 languages, if the findings observed in Experiment 1 are related to this ongoing language development and acquisition of vocabulary and literacy, we may observe different patterns in adults.

\section{Methods}

Participants. Forty-eight adults took part in this experiment ( 30 females; $M_{\text {age }}=21.68$

Table 5. Descriptive statistics of assessments.

\begin{tabular}{|c|c|c|c|c|}
\hline & & panish-Basque & & \\
\hline & Monolinguals & bilinguals & $\mathbf{t}(d f)$ & $p$ \\
\hline Age & $21.33(3.12)$ & $22.04(2.47)$ & $t(46)=0.84$ & .403 \\
\hline Spanish competence & $9.41(1.83)$ & $9.12(0.79)$ & $t(46)=0.71$ & .408 \\
\hline Basque competence & $0(0)$ & $9.29(0.80)$ & - & - \\
\hline Spanish LexTale & $90.34(6.70)$ & $92.84(3.84)$ & $t(46)=2.05$ & .142 \\
\hline Basque LexTale & $0(0)$ & $91.08(4.45)$ & - & - \\
\hline Spanish picture naming & $18.83(1.94)$ & $19,54(0.58)$ & $t(46)=2.81$ & .158 \\
\hline Basque picture naming & $0(0)$ & $17.95(1.39)$ & - & - \\
\hline Socioeconomic status & $6.58(0.88)$ & $7(0.78)$ & $t(46)=2.72$ & .142 \\
\hline IQ & $20.83(1.83)$ & $21.79(2.48)$ & $t(46)=2.31$ & .133 \\
\hline
\end{tabular}


424 The study was approved by the BCBL Ethics Committee and all participants signed an informed consent before the experiment and were compensated for their time. None of them were lefthanded and none were diagnosed with language disorders, learning disabilities, or auditory impairments. and Levenshtein distance in the recall task and percentage of errors and reaction times in the recognition task. In the recall task, participants recalled more legal than illegal orthotactic sequences, $F(1,46)=16.92, p=<.001, \eta_{p}^{2}=.262$, but groups did not differ on performance, $F(1$, 46)=0.47, $p=.492, \eta_{p}^{2}=.010$, and there was no interaction between Group and Orthotactic Structure, $F(1,46)=1.57, p=.217, \eta_{p}^{2}=.024$. The analysis of Levenshtein Distance showed that 440 the recall of legal orthotactic sequences was closer to the template than that of illegal 441 sequences, $F(1,46)=51.97, p=<.001, \eta_{p}^{2}=.506$. Also, a Group effect was found, $F(1,46)=11.54$, $p=.001, \eta_{p}^{2}=.201$, such that the Spanish-Basque bilinguals outperformed the monolinguals. The interaction between the two factors was significant, $F(1,46)=4.83, p=.033, \eta_{p}^{2}=.047$, suggesting 
444 that Spanish-Basque bilingual adults' recall was more similar to the target items, especially in

445 the case of the legal sequences (see Table 6).

Table 6. Descriptive statistics for the Recall task and the Recognition task

\begin{tabular}{lcccc}
\hline \multicolumn{2}{c}{ Monolinguals } & \multicolumn{2}{c}{ Spanish-Basque bilinguals } \\
\hline Legal & Illegal & Legal & Illegal \\
\hline Recall task & & & & \\
LD & $1.04(1.90)$ & $0.38(1.44)$ & $1.63(2.26)$ & $0.38(0.58)$ \\
& $5.69(1.09)$ & $6.18(0.86)$ & $4.58(1.18)$ & $5.51(0.66)$
\end{tabular}

Recognition task

$\begin{array}{lrrrr}\text { \%error } & 25.83(12.64) & 35.83(19.14) & 11.11(13.43) & 24.72(11.37) \\ \text { RT } & 1974(444) & 2256(637) & 1899(433) & 2318(642)\end{array}$

Note. Mean and standard deviation in parenthesis on recalled items (absolute number) and Levenshtein Distance

449 (LD) (Recall task) and \%error and reaction times in ms (Recognition task) for legal and illegal orthotactic sequences

450 for the three language groups.

451

In the recognition task, adults showed a main effect of Orthotactic Structure on the

percentage of errors, $F(1,46)=31.05, p=<.001, \eta_{p}^{2}=.399$, as well as of Group, $F(1,46)=12.91$,

$p=<.001, \eta_{p}^{2}=.219$, but not an interaction, $F(1,46)=0.73, p=.399, \eta_{p}^{2}=.009$. This means that

adults recognized the legal orthotactic structures more accurately than the illegal ones, and

that Spanish-Basque bilinguals outperformed monolinguals in the overall learning (see Fig 3).

However, the absence of interaction suggested that both language groups remembered the

460 illegal ones, $F(1,46)=28.14, p=<.001, \eta_{p}^{2}=.374$. However, there was no Group effect, $F(1$, 
Fig 3. Violin plots of the percentage of errors in legal and illegal orthotactic sequences. monolingual adults, as children did, in the way they learn new legal and illegal words. Similar to the results reported in Experiments $1 \mathrm{a}$ and $1 \mathrm{~b}$, the recall task showed that both language groups recalled more legal than illegal words. However, unlike in Experiment 1, the recognition task showed a legality effect for both language groups. Both the Spanish monolinguals and the Spanish-Basque bilinguals remembered legal words better than illegal words. In terms of overall performance, Spanish-Basque bilinguals outperformed Spanish monolinguals: bilinguals remembered more words than monolinguals in the recognition task and their responses in the recall task were closer to the target words. bilinguals compared with monolinguals (for a review, see [27]), aligning with previous studies

477 focused on adult word learning showing that bilinguals outperform monolinguals $[4,9,11,28]$.

478 The results from Experiment 2 provide support to this view, suggesting that bilinguals can benefit from their previous experience with language (e.g., learning vocabulary in various languages) to achieve a higher level of performance in new word learning tasks. However, performance. 
487 word learning due to their experience with language learning [4,9]. The aim of the present

488 study was to examine whether new word learning is driven by the bilingual experience itself,

489 or rather the specific linguistic experience with the languages in the bilingual pair. We were

490 specifically interested in whether greater language difference can give an edge in novel word

491 learning. Therefore, we conducted two experiments to test this hypothesis. In Experiment 1,

492 we asked children to learn new words containing legal or illegal patterns. Specifically, in

493 Experiment 1a we tested children that were Spanish-Basque bilinguals, Catalan-Spanish

494 bilinguals, or Spanish monolinguals and in Experiment $1 \mathrm{~b}$ we tested two additional groups of

495 Spanish-Basque bilinguals in an attempt to replicate the findings and control for the effects of

496 proficiency. In a second experiment, we carried out the same task as in Experiment 1, but with

497 two groups of adults (Spanish monolinguals and Spanish-Basque bilinguals) in order to test

498 whether the effects were only present in the process of language development.

499 In Experiment 1a, we observed that the children in all three language groups recalled

500 legal items better than illegal ones, in line with prior literature showing that it is easier to learn

501 items that correspond with our prior knowledge [14]. No effects of language group were

502 observed. However, this recall task is not very informative due to the low percentage of words

503 the children were able to properly recall. This low performance could lead to a floor effect, in

504 which we cannot observe a difference between groups simply because performance does not

505 allow for enough variability [29]. A greater amount of rehearsal might be needed to enhance

506 recall performance and show further effects of language group. Due to the difficulty of the

507 task, recognition memory may be more sensitive to showing the nuanced effects of language

508 group. Indeed, in this task Spanish-Catalan bilinguals and Spanish monolingual children

509 showed a benefit for legal items, whereas Spanish-Basque bilingual children did not. In other

510 words, Spanish-Basque bilingual children did not show a legality effect, and they recognized

511 legal and illegal (namely, orthographically unmarked and marked) strings similarly. 
512 Importantly, the results of Experiment $1 \mathrm{~b}$ with two additional groups of Spanish-Basque

513 bilingual children demonstrated that the absence of a legality effect in this population is a

514 stable phenomenon that does not depend on the level of proficiency.

515 Focusing on the language group differences in the recognition task, both monolinguals

516 and Spanish-Catalan bilinguals follow the patterns of learning that are described in prior

517 literature [14]-namely, they learn legal sequences better than illegal ones-whereas the

518 Spanish-Basque bilinguals deviate from this. Our hypothesis is that the driving factor leading to

519 this differential effect could be linguistic experience, meaning that by learning (or knowing)

520 two languages that differ very strongly in their orthotactic rules, these bilinguals are less

521 affected by the legality of new words. That is, Spanish-Basque children could be less sensitive,

522 and thus more flexible, to the legality of words due to their experience with languages that

523 already have patterns that violate the rules in the other language. In particular, Spanish and

524 Basque differ strongly in their orthotactics rules, which is not so much the case with Spanish

525 and Catalan. This experience of managing two different sets of rules is what sets this group of

526 Spanish-Basque bilinguals apart and may have allowed them to learn words equally regardless

527 of whether their orthotactic patterns violated the rules in the already known languages.

534 legality effect. That is, contrary to the children, both the Spanish monolingual and the Spanish-

535 Basque bilingual adults recognised legal words better than illegal words, and the former group

536 had an overall poorer performance than the latter one. 

children and adults, we tentatively suggest that they are due to already acquired linguistic

539 competence in the adults and the still ongoing language and cognitive development in 540 children. The ability to learn a new language changes across the lifespan and children may acquire new languages and new vocabulary in a different manner than adults [30]. Children that are still learning a language, learn more vocabulary and have a greater amount of exposure to new language elements (e.g., rules, vocabulary, complex sentences) than adults

544 [31]. In contrast, adults undergo fewer changes in the language development of the languages

they already speak. Thus, considering that children can be more flexible at learning new words children, but not adults, learn legal and illegal new words equally well. The group of children were still in the process of conforming to the Basque and Spanish vocabulary, a process that could have made them less sensitive to illegality. On the other hand, adults who have already fully acquired both languages may have also developed sensitivity to differences between languages, something that they can use as a strategy in some circumstances (see [19] for a review). Thus, contrary to children, Spanish-Basque adults may be sensitive to legal versus illegal orthotactic patterns and may consequently show better performance for legal words. In sum, having experience with languages that differ at the orthographic (or orthotactic), but also phonotactic, level can affect word learning. Bilingual children who are 


\section{Supporting Information}

564 S1 Appendix. Thirty new words with their average bigram frequency (appearance per 565 million). Bigram frequency is calculated averaging the frequencies of the critical consonantal 566 bigrams. The items are numbered in the same order as in S2 Appendix.

567 (PDF)

568

\section{Acknowledgments}

570 This research has been partially funded by grant PSI2015-65689-P from the Spanish 571 Government to JAD, by the AThEME project funded by the European Union (grant number 572 613465), by a personal grant from La Fundación La Caixa ID 100010434 to MB (code 573 LCF/BQ/ES16/11570003), and by grant Centro de Excelencia Severo Ochoa SEV-2015-0490 by 574 the Spanish Government. The funders had no role in study design, data collection and analysis, 575 decision to publish, or preparation of the manuscript.

577 Author contributions: RdD MDV VV VH. 
586 1. Bialystok E, Klein R, Craik FIM, Viswanathan M. Bilingualism, aging, and cognitive control: Evidence from the Simon task. Psychol Aging. 2004;19(2):290-303.

2. Bialystok E, Luk G, Kwan E. Bilingualism, biliteracy, and learning to read: Interactions among languages and writing systems. Sci Stud Read. 2005;9(1):43-61.

3. Colzato LS, Bajo MT, van den Wildenberg W, Paolieri D, Nieuwenhuis S, Heij W La, et al. Reactive Inhibition Mechanisms. J Exp Psychol Learn Mem Cogn. 2008;34(2):302-12.

4. Kaushanskaya M, Marian V. The bilingual advantage in novel word learning. Psychon

5. Cenoz, J.; Valencia JF. Additive trilingualism: Evidence from Basque country. Applied

6. SANZ C. Bilingual education enhances third language acquisition: Evidence from Catalonia. Appl Psycholinguist [Internet]. 2000;21(1):23-44. Available from: http://www.journals.cambridge.org/abstract_S0142716400001028

11. Kaushanskaya M, Rechtzigel K. Concreteness effects in bilingual and monolingual word

12. Werker JF, Byers-Heinlein K. Bilingualism in infancy: first steps in perception and

13. Bent $T$, Bradlow AR, Wright BA. The influence of linguistic experience on the cognitive

14. Ellis NC, Beaton A. Psycholinguistic Determinants of Foreign Language Vocabulary

15. Lemhöfer K, Koester D, Schreuder R. When bicycle pump is harder to read than bicycle bell: Effects of parsing cues in first and second language compound reading. Psychon Bull Rev. 2011;18(2):364-70.

16. Van Kesteren R, Dijkstra T, de Smedt K. Markedness effects in Norwegian-English bilinguals: Task-dependent use of language-specific letters and bigrams. Q J Exp Psychol. 2012;65(11):2129-54. 
specific words in bilinguals. Q J Exp Psychol. 2016;69(3):589-604.

627

628

629

630

631

632

633

634

635

636

637

638

639

640

641

642

643

644

645

646

647

648

649

650

651

652

653

654

655

656

18. Vaid J, Frenck-Mestre C. Do orthographic cues aid language recognition? A laterality study with French-English bilinguals. Brain Lang. 2002;82(1):47-53.

19. Casaponsa A, Carreiras M, Duñabeitia JA. Discriminating languages in bilingual contexts: The impact of orthographic markedness. Front Psychol. 2014;5(MAY):1-10.

20. Casaponsa A, Carreiras M, Duñabeitia JA. How do bilinguals identify the language of the words they read? Brain Res [Internet]. 2015;1624:153-66. Available from: http://dx.doi.org/10.1016/j.brainres.2015.07.035

21. de Bruin A, Carreiras M, Duñabeitia JA. The BEST dataset of language proficiency. Front Psychol. 2017;8(MAR).

22. Lemhöfer K, Broersma M. Introducing LexTALE: A quick and valid Lexical Test for Advanced Learners of English. Behav Res Methods. 2012;44(2):325-43.

23. Izura C, Cuetos F, Brysbaert M. Lextale-Esp: A test to rapidly and efficiently assess the Spanish vocabulary size. Psicológica. 2014;43(4):559-617.

24. Adler N, Stewart J. The MacArthur scale of subjective social status. MacArthur Research Network on SES \& Health. 2007.

25. Kaufman AS. KBIT: Kaufman Brief Intelligence Test (KBIT, Spanish version). madrid: TEA Editions; 2004.

26. Antón E, Thierry G, Duñabeitia JA. Mixing languages during learning? Testing the one subject-one language rule. PLoS One [Internet]. 2015;10(6):1-20. Available from: http://dx.doi.org/10.1371/journal.pone.0130069

27. Hirosh Z, Degani T. Direct and indirect effects of multilingualism on novel language learning: An integrative review. Psychon Bull Rev. 2018;25(3):892-916.

28. Bartolotti J, Marian V. Language Learning and Control in Monolinguals and Bilinguals. Cogn Sci. 2012;36(6):1129-47.

29. Baddeley A. working memory. Science (80- ). 1992;255(5044):556-9.

30. Newport EL. Maturational Constraints on Language learning. Cogn Sci [Internet]. 1990;14(1):11-28. Available from: http://www.journals.cambridge.org/abstract_S0272263100009165

31. Shipley KG, McAfee JG. Assessment in speech-language pathology: A resource manual. Nelson Education. 2015. 


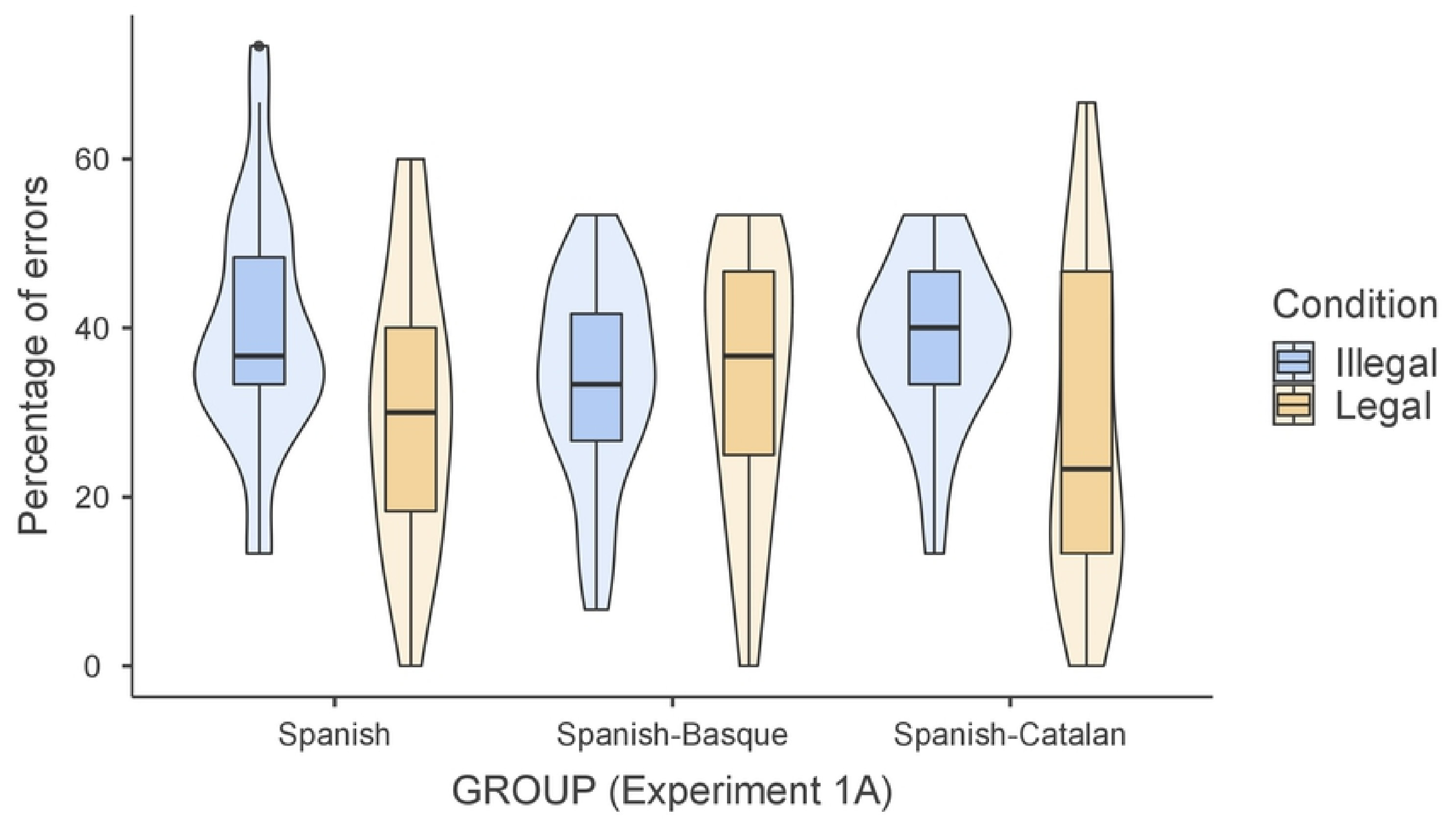

Figure 1 


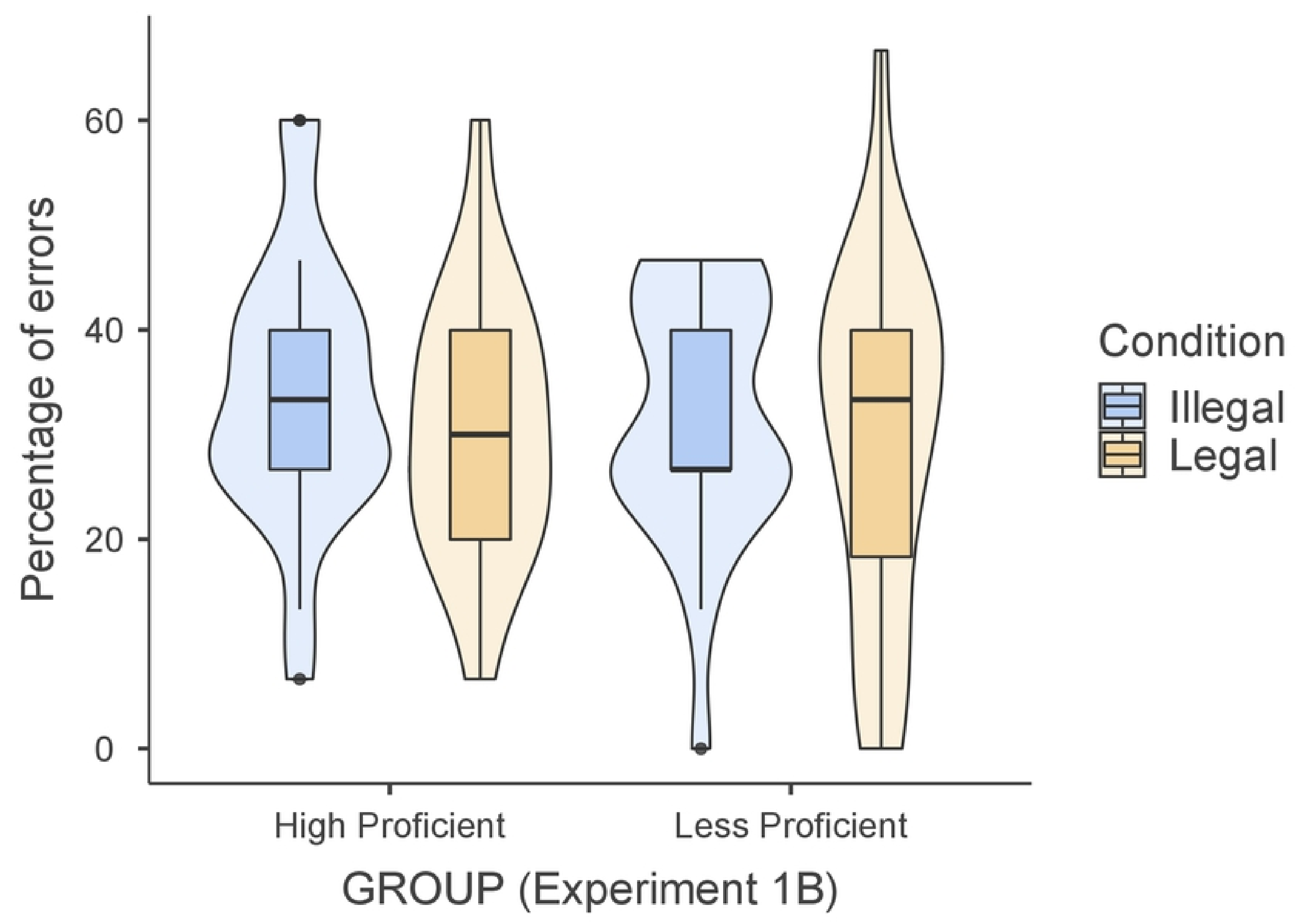

Figure 2 


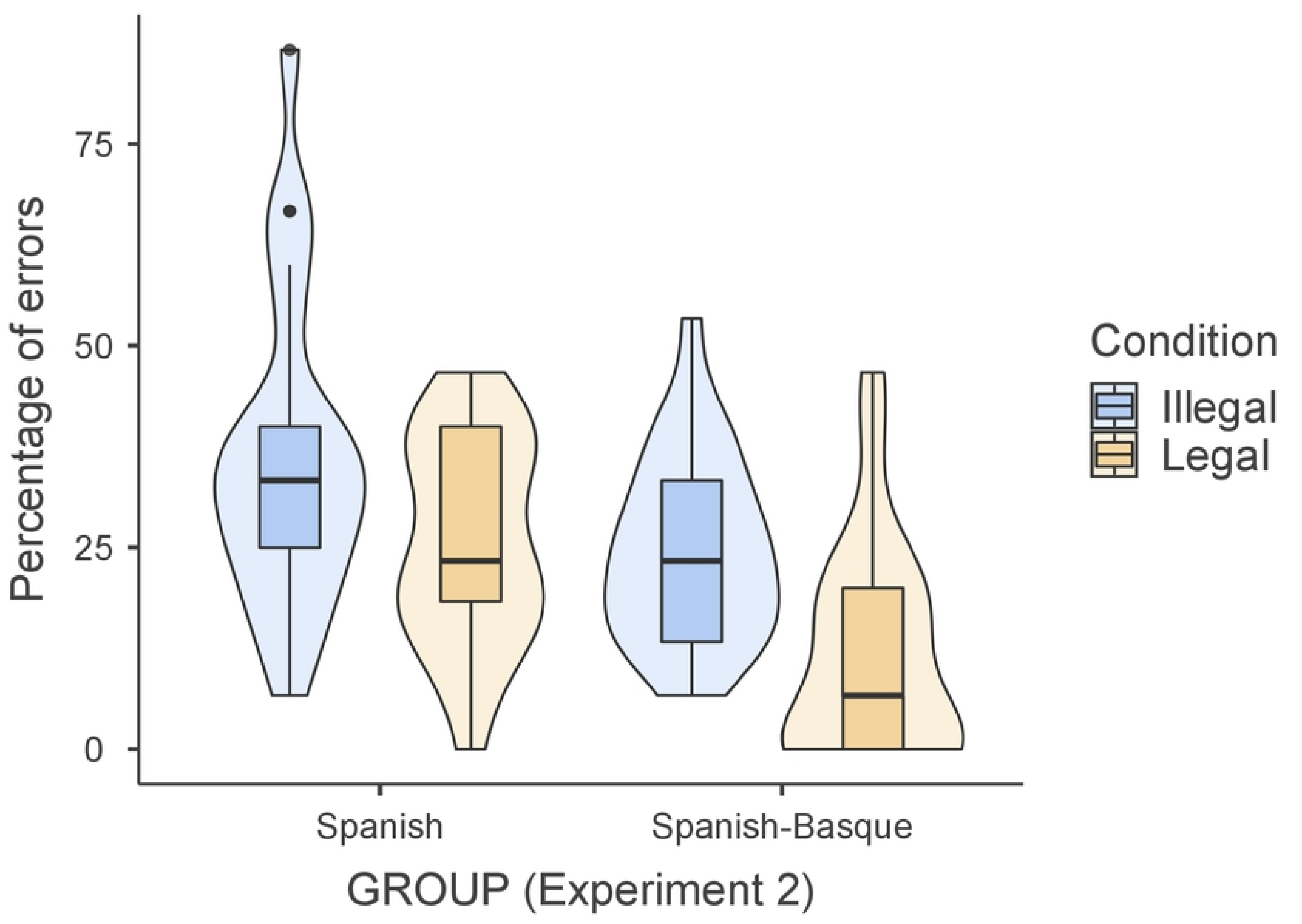

Figure 3 